\title{
Bruxism - description, epidemiology, etiology, classification
}

\author{
Radostina Vasileva ${ }^{1}$
}

1. Department of Dental Material Science and Propaedeutic of Prosthetic Dental Medicine, Faculty of Dental Medicine, Medical University Varna;

\begin{abstract}
In the normal social and personal environment each person performs functions needed for its existence and development. These functions like eating, chewing, talking and more are a natural act. They are a vital necessity. In some cases, man also performs unnatural, unnecessary actions for its normal developmental activities and functions that are known as parafunctions. The parafunctions in the chewing area can be divided to: occlusal type - with the active involvement of the occlusal dental surface, non-occlusal type - with the active involvement of the lips, the cheeks and the muscles, of course not without the involvement of the dental surfaces. One of the main and often occurring parafunction of the occlusal type is bruxism.
\end{abstract}

Keywords: bruxism, parafunction, clenching, squeaking, joint, gnathology.

\section{Introduction}

Historical evidence of the creaking of teeth exists still in the Bible (Job 16:9); and the term "bruxomania" has been used in specialized literature since the beginning 20th century.

The word bruxism means "squeaking", derived from new latin - "Bruxis" and from greek - "Brukein". Bruxism is a parafuction consisting of clapping and gnashing of teeth usually at night, but also in a state of stress and nervous pressure.(1) 
The American Academy of Maxillofacial Disorders defines Bruxism as daily or night-time para-functional activity, which includes clenching, squeaking, creaking and tooth friction. The American Sleep Disorders Association defines sleeping bruxism as a periodically stereotypically injurious movement characterized by clenching or creaking of the teeth during sleep.(2)

Caroly introduces the term dental neuralgia, which term suggests, not in an ambiguous way, the nature of Bruxism as a symptom of a nervous damage. In 1907 Marie and Pietrickevich goes far and calls it mania or bruxomania with a slightly disturbing element of obsession.(3)

In 1931 Froman calls the problem "Bruxism" by borrowing the verb from the Greek and the Latin nomenclature. (4)

In 1962 Drum defines Bruxism as parafunction and more like abnormal function beyond the natural need.

Perhaps no other dental disease represents a so complex link between psychiatry and psychology on one hand and the dental medicine on the other. With a major etiological factor - disorder of the nervous system, the bruxism is a striking example of the deep and inseparable relationship between dentistry and medicine.(5.6)

Bruxism is a widespread illness in view of the tense life of the modern man. Due to different survey methods, operational definitions, clinical criteria and study groups, most of the symptoms of Bruxism differ among the cases for the adults and for the children.(7.8)

Most patients show signs of bruxism that the dentist can observe - such as worn tooth surfaces. Patient reports have found teeth clenching in about $20 \%$ in waking hours compared to $10 \%$ during sleep and friction of teeth ranging between $6 \%$ and $12 \%$. Other studies have shown that up to $90 \%$ of people have bruxism. Between 40 and 50 years most people have bruxism up to degree of clenching capable to destroy their dental restorations.(9.10.11)

According to statistics, bruxism has spread to $5 \%$ to $20 \%$ from the people and 1 of every 20 has bruxism. In the developed countries USA, Canada, Japan up to $80 \%$ of people have bruxism. In the US over 30 million Americans have bruxism from and up to $10 \%$ cling to a force capable to destroy their teeth. Statistics also indicates that bruxism is the third most harmful and frequent habit after talking at night and snoring. Especially often affected by bruxism are also the children.(12.13.14)

To determine the actual spread of bruxism is difficult because this parafunctional mandibular manifestation is unconscious for most of the individuals. Because of this limitation, the individual is more dependent on a husband or a cohabitant who, through the sounds of the forces of bruxism, can determine the presence of clenching or rubbing of the teeth. Although that studies show that the manifestations of bruxism are most common from the teenage years to the age of forty and that this parafunctional behavior disappears with age, there is not a sufficient evidence whether bruxism could be observed in individuals with dentures. $(15.16 .17 .18)$

According to clinical studies during sleep, in patients with whole dentures, symptoms of bruxism appear. In terms of gender distribution, studies show more often parafunctions in women rather than men, but 
according to clinical observations the distribution is almost equal. Another study shows a lack of gender differences in the bruxism signs for the common population.(19.20)

After all of the reasons we could believe that bruxism is a disease that should be treated. The coughing and gnashing can be through the day and the night with varying intensity and increasing power. Deeper clinical observation will find the connection between tooth surfaces, periodontium, mucous membrane, temporomandibular joint and muscles in the light of their injury.(21.22)

The etiology of Bruxism is complicated and in some aspects not sufficiently established and explained. We can talk about polyetiological disease - a disease caused by numerous factors. Two groups are the most common - the occlusal factors or disturbances and the psychophysiological factors. The first group includes the occlusal interferences that obstruct the normal orthogonal bite. Historically, the occlusal disorders were perceived as bruxism-accelerating factors. The conclusion was that the patient makes an unconscious attempt to balance or adapt his or her dent to eliminate the disruption, mainly through nightly bruxism. The last research does not support the direct relationship between night-time bruxism and the interference of the individual occlusion. In fact, according to other researchers, patient reactions to occlusal discomfort are more important than the disturbance itself.(23.24)

Another study suggests the probability that the ability of the individual occlusion to tolerate the forces generated by bruxism is preferable instead of creating an occlusion that would seem to eliminate the manifestations of bruxism. So it is possible for the dentist to find out that the teeth relationship can be a factor for the manifestations of bruxism and its destructive consequences on them. Exists an opinion that from all functional tooth disorders bruxism has the most devastating effect. High obturations, bridges and crowns, and a change in the height of the bite are common causative agents. Disturbance of the occlusal equilibrium, disturbance of the occlusion balance and most of the pathophysiological bites may be the cause for bruxism. Some of the occlusal factors are hereditary or acquired, others are the result of improper dental treatment. (25.26)

The second group of factors is psychophysiological. The world literature gives a big meaning of the psychophysiological component of bruxism. An example could be given by the fact that, in severe occlusion disorders, people with stable nervous system do not develop bruxism, and the opposite - for patients with perfect occlusion and development of the dental system but with a labile psyche, severe forms of bruxism could be developped. Psychic or mental factors are activator of the process. This includes mild forms of neurosis, fear, anxiety, frustration / failure to fulfill the desires /, tension, anxiety. Aggressive, hyperactive and personality with complexes are particularly susceptible to bruxism. Physiological factors include increased hot and cold sensitivity, hypoglycaemic states, diabetes, some abdominal diseases such as gastritis, abdominal tapeworms, parasitoses. Some brain diseases can cause bruxism. Mineral imbalance and lack of vitamins also cause the disease. When taking antidepressants, such as Zoloft, Paxil, Prozac, Sarafen and others, as a side effect appears bruxism. Taking coffee and cigarettes in large quantities can cause the formation of large amounts of adrenaline, so it could provoke bruxism. The occurrence of the disease as a result of heredity predisposition could not be completely rejected.(27.28)

In the systematization of this common illness the major role is played by the classification that Ramfjord and Ash make in 1971 in its famous monography "Occlusion", dividing the bruxism into two types. Centric or static type and eccentric or sliding type. (29) 
Other authors divide Bruxism into sleeping and awake as a result of whether he is during the night sleep or during the daylight hours.(30) Another classification of bruxism is devided by the nocturnal and the daily type in which respectively, the patient may have sleeping bruxism during the day and awake bruxism at night - so here the reference point is the sleep, not the sunlight.(31)

Miller in 1936 divides the disease into bruxism and bruxomania. The classification of the bruxism is important in view of the separation of the different types with different clinical picture and differential diagnosis. (32)

\section{Conclusion}

Tense lifestyle, improper treatment, severe traumas are the conditions to develop this harmful habit called bruxism. Especially developed in advanced societies, characterized by tension and the modern life, the bruxism is a significant disease. It damages the dental structures, the joints and the muscles. It creates a change in the lifestyle, degrading the nutrition and the comfort. Knowing this disease is a major task and the prevention has a big role. The modern science finds a link between the local changes in the dental system and the whole body, which is an indisputable fact for the need of complex treatment of the problem.

\section{References}

1. Allen DL. Accurate occlusal bite guards. Periodontics. 1967;5:93-95

2. Amir I, Hermesh H, Gavish A. Bruxism secondary to antipsychotic drug exposure: a positive response to propranolol. Clin Neuropharmacol. 1997;20:86-89.

3. Boyd JP. Improving TMD treatment and protecting restorative dentistry. Dent Today. 1998;17:144.

4. Cannistraci AJ. A method to control bruxism: biofeedback assisted relaxation therapy. J Am Soc Prev Dent. 1976;6:12-15.

5. Cherasia M, Parks L. Suggestions for use of behavioral measures in treating bruxism. Psychol Rep. 1986;58:719-722.

6. Christensen G.J. Destruction of human teeth.J. of American Dental Association, ,1999.

7. Clark GT, Beemsterboer PL, Solberg WK, Rugh JD. Nocturnal electromyographic evaluation of myofascial pain dysfunction in patients undergoing occlusal splint therapy. J Am Dent Assoc. 1979;99:607-611.

8. Clark, G. T., Koyano, M. S., \& Browne, P. A. (1993). Oral motor disorders in humans. CDA Journal , 21, 19-30.

9. Clarke J.H. and Reynolds .P.J. Suggestive hypnotherapy for nocturnal bruxism ,a pilot study.American Journal of Clinical Hypnosisi, 1991 Apr;33(4):248-53.

10. Kydd WL, Daly C. Duration of nocturnal tooth contacts during bruxing. J Prosthet Dent. 1985 May;53(5):717-

11. Etzel KR, Stockstill JW, Rugh JD, Fisher JG. Tryptophan supplementation for nocturnal bruxism: report of negative results. J Craniomandib Disord. 1991;5:115-120.

12. Greene CS, Klasser GD, Epstein JB. 'Observations' questioned. J Am Dent Assoc. 2005;136:852853.

13. Hartman E.Bruxism in M.H. Kryger.T.Roth and W.C.Demen.Principles and practice of sleep medicine.2010.

14. Holmgren K, Sheikholeslam A. Occlusal adjustment and myoelectric activity of the jaw elevator muscles in patients with nocturnal bruxism and craniomandibular disorders. Scand J Dent Res. 1994;102:238-243. 
15. Huynh N, Lavigne GJ, Lanfranchi PA, Montplaisir JY, Champlain J. The effect of 2 sympatholytic medications-propranolol and clonidine on sleep bruxism: experimental randomized controlled studies. Sleep. 2006;29:307-316.

16. Landary ML, et al. Reduction of sleep bruxism using a mandibular advancement device: an experimental controlled study. Int J Prosthodont. 2006;19:549-556.

17. Lavigne GJ, Rompre PH, Montplaisir JY, Lobbezoo F. Motor activity in sleep bruxism with concomitant jaw muscle pain: a retrospective pilot study. Eur J Oral Sci. 1997;105:92-95.

18. Leib AM (1996) The occlusal bite splint-a noninvasive therapy for occlusal habits and temporomandibular disorders. Compend Contin Educ Dent 17:1081-1084, 1086, 1088

19. Lerman .M.D. The hydrostatic splint . The Journal of the American Dental Association Volume 89, Issue 6, December 1974, Pages 1343-1350.

20. Lobbezoo F1, Soucy JP, Montplaisir JY, Lavigne GJ. Striatal D2 receptor binding in sleep bruxism: a controlled study with iodine-123-iodobenzamide and single-photon-emission computed tomography. J Dent Res. 1996 Oct;75(10):1804-10

21. Long J.H.,Jr. A device to prevent jaw clenching, J Prosthet Dent. 1998 Mar;79(3):353-4.

22. Mittelman J. Biofeedback: new answer to dental pain. It can be administered easily and inexpensively in any dental office. Dent Manag. 1976;16(21-22):26-27.

23. Monroy PG, Da Fonseca MA. The use of botulinum toxin-a in the treatment of severe bruxism in a patient with autism: a case report. Spec Care Dent. 2006;26:37-39.

24. Nash MC, Ferrell RB, Lombardo MA, Williams RB. Treatment of bruxism in Huntington's disease with botulinum toxin. J Neuropsychiatry Clin Neurosci. 2004;16:381-382.

25. Nassif NJ, Al-Ghamdi KS (1999) Managing bruxism and temporomandibular disorders using a centric relation occlusal device. Compend Contin Educ Dent 20:1071-1074, 1076, 1078, 1086

26. Nissani M. Can taste aversion prevent bruxism? Appl Psychophysiol Biofeedback. 2000;25:43-54.

27. Okeson JP. The effects of hard and soft occlusal splints on nocturnal bruxism. J Am Dent Assoc. 1987;114:788-791.

28. Pierce,C.J. and Gale E, A comparision of different treatments for nocturnal bruxism.J. of Dental Research,1988 Mar;67(3):597-601.

29. Ramfjord, Ash, Occlusion, Published by W B Saunders -1971, 120-134

30. Ronald Attanasio, An overview of bruxism and its management. Dent Clin North Am. 1997 Apr;41(2):229-41.

31. Sullivan TC. A new occlusal splint for treating bruxism and TMD during orthodontic therapy. J Clin Orthod. 2001;35:142-144.

32. Tan EK, Jankovic J. Treating severe bruxism with botulinum toxin. J Am Dent Assoc. 2000;131:211216.

\section{Corresponding author:}

Radostina Vasileva,

Department of Dental Material Science

and Propaedeutics of Prosthetic Dental Medicine,

Faculty of Dental Medicine,

Medical University Varna,

email: radost11dent@abv.bg 